\title{
The Importance of Reasonably Allocating Time in Architectural Drafting and CAD Lectures
}

\author{
Zhijia Pan ${ }^{1, a^{*}}$, Haiqing Yuan ${ }^{2, b}$ and Shouzeng Zhu ${ }^{3, c}$ \\ 1,2Wuchang Shouyi University, China \\ ${ }^{3}$ Guilin University of Technology, China \\ axiaofeixiafeifei@126.com, byuanhq126@126.com, cshouzeng@glite.edu.cn
}

Keywords: Drafting, Method, Point, Minute, Score.

\begin{abstract}
Four classes from two grades in the same major were given lectures of architectural drafting and CAD successively by the same lecturer in last two years. Grade 2015 were given lectures by the traditional method which favors teaching and practicing apart. Grade 2016 were given lectures by a new method which unites teaching and practicing as an organic system with more concern of how the students learn and perform. Compare the real-time performance in class and the outcome of tests both in class and final examinations, the new method proves to be more efficient and more suitable for the new generation of students in the major of civil engineering.
\end{abstract}

\section{Introduction}

Architectural drafting is an indispensable course for students in the filed of civil engineering to understand the origins, the processes and the outcomes of what they are learning and what they will work at after graduation. It provides a bridge from imagination of civil engineers to their projects. The roads, bridges, tunnels, dams, harbors, power plants, water and sewage systems, hospitals, schools, mass transit, houses, buildings and other public or private facilities essential to modern even ancient society do not come from nothing or just a piece of thought. They stem from the well-round and rightly structured designs of civil engineers. To convert all the designs into practical facilities, architectural drafting is needed to offer builders various kinds of blue prints that also have been known as architectural drawings for construction to depend on so that the work can be done at sites.

$\mathrm{CAD}$, computer aided drafting, was brought into college curriculum rather late because usage of computers was only available in the very last few years of last century. Many researches since have been rolled out to discuss how to make students learn better of the courses in this field. Architectural drafting and CAD are two different courses but relate to each other like no other ones[1,2]. Architectural drafting aims to teach students the basic knowledge of understanding their future work items, architectural drawings for construction. Projection of points, lines and planes paves the road to projection of objects and structures like houses and buildings. CAD teaches students how to use what they learn from the former course through computers. Thus looking back on the researches, a large portion went on the track of combination of these two[3,4]. They have been proved quite successful as lots of colleges did put the results into practice. Text books nowadays have already combine the two parts together.

\section{Preparation}

\subsection{Existent Problems}

Wuchang Shouyi University sets up the course of Architectural Drafting and CAD in the fourth semester of the second year. As the arrangement requires, Architectural Drafting part ought to be lectured prior to CAD part. What was observed from grade 2015 was that students usually forgot what they learned in the former part when learning the latter part, and the lecturer had to again cover the missed parts by interrupting the normal schedule and re-lectured the old knowledge. Students could not follow the lecturer's steps in and after class. Late submission of homework, slow response 
to questions and practices during class, decreasing numbers of attendees gave an obvious clue that something about the lecture went in the wrong direction. Both the students and the lecturer felt frustrated and the final examination was disappointing. This triggered the experiment of improving efficiency of the lectures and performance of the students.

\subsection{Analysis of feasibility}

The textbook chosen for the lecture is one of most widely used version written by He Bin, Chen Jingchang, Wang Fenghong and organized by several universities such as South China University of Technology and Hunan University. It has been revised for 6 times and now the 7 th edition is quite useful for fresh learners because it includes all the drafting knowledge that has been considered necessary to the major of Civil Engineering. Together it has 19 chapters, 7 of which have been taught in preliminary class a year before, 5 of which were not suitable for the major. Thus only 7 chapters are our main targets in learning.

Table 1. Chosen chapters for lectures.

\begin{tabular}{cc}
\hline Chapter & Theme \\
\hline Chapter1 & Introductions \\
\hline Chapter2 & Basic Requirements of Drafting \\
\hline Chapter10 & Architectural Drawings for Construction \\
\hline Chapter11 & Structural Drawings for Construction \\
\hline Chapter12 & Decoration Drawings for Construction \\
\hline Chapter13 & Plumbing Drawings \\
\hline Chapter19 & Computer-Aided Drafting and Design \\
\hline
\end{tabular}

Note: The corresponding parts of practice book were also chosen.

The chosen chapters have covered the most significant branches of engineering drafting. After one whole cycle of lectures with grade 2015, characteristics of this textbook was confirmed that combination of the hand drafting and computer drafting is a difficult part for fresh learners. Students usually forgot the basic knowledge appeared in the first few weeks and could not use the computer to do the job smoothly. Learning CAD itself is somewhat overwhelming for a number of students since the software is distinctively different from the often used ones like Office or WPS. It has more tools and buttons to remember, more commands to practice and apply. Recognition of each tool can cost much time, usage of those tools to complete the work within principles of the major is a more time-consuming task.

\subsection{Prerequisites}

Class 1503, 1504 and class 1601, 1602 were chosen to be applied different teaching methods. It had better be that one same lecturer gave out lectures to these two grades using the same textbook from which the same content were chosen. Also the fact that the two grades are from the same major in the same college is important. Both grades were having lectures distributed into 17 weeks and were taught 4 lessons half a day each week. 4 lessons in one half day is a challenge for anyone from any major, and that gave the lecturer more difficulties than those from other majors. All this could reduce the differences between the samples as much as possible in the experiment to make sure the diversity in the result stems from teaching methods not from other factors such as study environment, weather or even administration habits.

\section{Process and comparison}

\subsection{Traditional method}

The traditional way to lecture the course of engineering drafting and CAD is to put the half day of lectures into two sections. The first section which usually contains the first two lessons is for lecturing what's on the textbook. Then the third and fourth lesson, the second section, is given to the students to practice by hand or by computer. Some researches has shown that this method creates wastes of time since intense learning from the first two lessons are not well digested and suddenly 
free time of practice gives students chances to space out. Classes with grade 2015 was exactly the situation that was observed by the lecturer. In the first few times of lectures, students were excited about the new field which they might have some understanding from the former course of descriptive geometry. The free time of practice gave them a feeling of relax, not like any other course in college. But gradually the free time seemed losing its excitement and attraction. Cell phones which were not prohibited in college became their toys again. Chatting with friends or strangers was more fun than practice with confusion. The examination was not so ideal neither. $r$ in Eq. 1 for grade 2015 is $14.3 \%$.

$$
\mathrm{r}=\mathrm{m} / \mathrm{n}
$$

$\mathrm{r}$ is the ratio of students who did not pass the final exam. $\mathrm{m}$ is the number of students who failed and $\mathrm{n}$ is the total number of students in each grade. $\mathrm{n}$ is 56 for grade 2015 and 61 for grade 2016.

\subsection{New method}

Most students responded well to the questions from the lecturer only a short amount of time after the learning points were taught. Some still responded well later in the class, but really few could do that after several days. The reasons have been found out to be distractions from cell phones, student activities, personal lives or just a feeling of disappointment of where they are at present [5,6]. Thus dividing the whole course of engineering drafting and CAD into a number of learning points like those traffic signs along the rode in long travels would be helpful for students to learn and practice in a more energetic way. The course takes 72 periods of lectures altogether in one semester, 24 of which are arranged for textbook learning and hand practice while the other 48 are arranged for CAD learning. The two parts are taken in two different places on campus. Since the arrangement can not be changed, the new method of lecturing goes down to the path where two angles should be considered.

Textbook learning and hand practice takes 24 lessons, that is 1080 minutes to fulfill. There are 31 learning points in this part, so every point costs 35 minutes. The lecturer gave the class 20 minutes to learn and 15 minutes to practice immediately after learning was done. To be able to do that, students went to the classroom with drawing tools and papers all the time in the first 6 weeks. The lecturer checked their work when they were practicing, gave comments and scores on their work after class. It was obvious that students in grade 2016 did better than students in grade 2015. They resolved the same difficulties faster. The quality of their work was better. CAD took 48 lessons, that was 2160 minutes altogether. There are 40 basic tools and 35 other basic commands in the software. Along with the transformation of hand drafting from the firs part into computer drafting, there are 90 learning points altogether in the second part. Each learning point needs about 24 minutes. So 14 minutes were given for lecturing and showing how to do it with $\mathrm{CAD}, 10$ minutes were given for practice.

\subsection{Results comparison}

In order to find out the difference that different teaching methods create, two respects are put on the table to be compared[7]. First, observation in class. Students from grade 2016 responded more actively than those from grade 2015 . They also performed better in practice and homework. The guidelines for drafting both by hand and by computer were better followed. When a new question came, students from grade 2016 resolved it with less time, sometimes even with more diverse answers. Second, results of final examinations. $r$ in Eq. 1 for grade 2016 is $6.6 \%$, which is smaller than almost half of that of grade 2015 as the total number of students in the latter is more than that of the former.

$$
\begin{gathered}
\mathrm{x}=\left(\mathrm{x}_{1}+\mathrm{x}_{2}+\ldots \mathrm{x}_{\mathrm{n}}\right) / \mathrm{n} \\
\mathrm{d}=\left(\mathrm{x}_{\mathrm{b}}-\mathrm{Xa}_{\mathrm{a}}\right) / \mathrm{x}_{\mathrm{a}}
\end{gathered}
$$

$\mathrm{x}$ in Eq. 2 is the average score of the course of descriptive geometry and architectural drafting and CAD of each grade. $\mathrm{x}_{1}, \mathrm{x}_{2} \ldots \mathrm{x}$ is the score of every student in each grade. $\mathrm{x}$ of descriptive geometry is 60.4 for grade 2015 and 66.4 for grade 2016. $x$ of architectural drafting and CAD is 66.7 for grade 2015 and 68.1 for grade 2016. $\mathrm{d}$ in Eq. 3 is the deviation of the average score of each course. $\mathrm{xa}_{\mathrm{a}}$ is the 
average score of grade 2015 and $\mathrm{x}_{\mathrm{b}}$ is the average score of grade 2016 for the same course. $\mathrm{d}$ of descriptive geometry is $9.9 \%$ while that of engineering drafting and CAD is $2.1 \%$.

The above results explains that the new teaching method reduces the number of students who failed the final examinations. The average score of the course of Engineering Drafting and CAD is increasing by $2.1 \%$, which also proves that the new method is working.

\section{Summary}

The experiment with its results display that time arrangement of lectures stands in a more and more important role in today's social and academic environment. To understand how human attention works for the best is the key to teach and learn. Long time learning without proper rest for digestion and practice would cause attention lost, making the class boring and dry. Long time practicing without prompt check and correction would make students easily space out. The new method in which appropriate interference in lectures allots time more reasonably for both the lecturer and students, thus generating better performance and achievements.

\section{References}

[1] X. Zhao, P. Z. Yu, Analysis of architectural drawing course teaching reform strategy, Journal of Zhejiang Shuren Unviersity, vol. 12, pp. 39-43, 2012.

[2] X. Zhao, Discussion on teaching practice reform of architectural drawing, Journal of Zhejiang Shuren University, vol. 15, pp. 62-66, 2015.

[3] Z. B. Su, A practical survey of the course of architectural drafting and CAD. Journal of Changchun University of Science and Technology, vol. 6, pp. 190-191, 2011.

[4] H. Q. Li, Combined teaching method of architectural drafting and CAD, China Science and Technology Information, vol. 22, pp. 168, 2005.

[5] Y. W. Wang, D. F. Yi, Survey on factors influencing the undergraduates' attention in class, Mei Tan Higher Education, vol. 25, pp. 114-116, 2007.

[6] P. Fu, Discussion of the combination of architectural drafting and CAD. Science and Technology Information, vol. 17, pp. 108, 2009.

[7] Z. J. Pan, H. Q. Yuan, S. Z. Zhu, Necessity of getting involved in learning special English of civil engineering, $3^{\text {rd }}$ International Conference on Education, Language, Art and Inter-cultural Communication, vol. 40, pp, 335-338, 2016. 